Check for updates

Cite this: RSC Adv., 2020, 10, 20552

Received 28th March 2020

Accepted 22nd May 2020

DOI: $10.1039 / \mathrm{dOra02852e}$

rsc.li/rsc-advances

\section{Metal-free syntheses of new azocines via addition reactions of enaminones with acenaphthoquinone followed by oxidative cleavages of the corresponding vicinal diols $\dagger$}

\author{
S. Hekmat Mousavi, ${ }^{a}$ Mohammad Reza Mohammadizadeh, ${ }^{\text {*a }}$ Satoru Arimitsu, \\ Dariush Saberi, (D) ${ }^{c}$ Samira Poorsadeghib ${ }^{\mathrm{b}}$ and Kojya Genta ${ }^{\mathrm{d}}$
}

A one-pot, clean and green procedure is described for the syntheses of new azocine derivatives via addition reactions of enaminones with acenaphthoquinone followed by periodic acid-mediated oxidative cleavages of the corresponding vicinal diols. Various derivatives of azocine were prepared and well characterized. The excellent yields, simple synthesis procedure, lack of a need to carry out any tedious work-up and column chromatography, metal-free catalysis, and mild reaction conditions are important features of this protocol.

\section{Introduction}

Eight-membered azocine rings are N-heterocyclic compounds that play a pivotal role in the structures of various important natural products as well as precursors in the syntheses of

${ }^{a}$ Department of Chemistry, Faculty of Sciences, Persian Gulf University, Bushehr 75169, Iran. E-mail: mrmohamadizadeh@pgu.ac.ir; Fax: +98-771-4541494

${ }^{b}$ Department of Chemistry, Biology and Marine Science, Faculty of Science, University of the Ryukyus, 1-Senbaru, Nishihara, Nakagami, Okinawa, 903-0213, Japan

'Marine Chemistry Department, Faculty of Marine Science and Technology, Persian Gulf University, Bushehr 75169, Iran

${ }^{d}$ Center for Research Advancement and Collaboration, University of the Ryukyus, Senbaru 1, Nishihara, Okinawa 903-0213, Japan

$\dagger$ Electronic supplementary information (ESI) available. CCDC 1976349. For ESI and crystallographic data in CIF or other electronic format see DOI: 10.1039/d0ra02852e biologically active compounds. ${ }^{1}$ Azocine derivatives have also found applications as therapeutic agents, such as antitussives, antihypertensives, analgesics, nasal decongestants, and antimalarials. ${ }^{2}$ These compounds are also structurally attractive, as they show interesting conformations. Because of unfavorable entropy and enthalpy factors, the azocine ring system is generally difficult to obtain, ${ }^{3}$ and relatively few methods are available for its preparation. However, there have been several general approaches used to construct azocine rings, including cycloaddition, ${ }^{4}$ the fragmentation reaction, ${ }^{5}$ Dieckmann cyclization, ${ }^{6}$ tandem hydroboration reactions, ${ }^{7}$ the Michael reaction, ${ }^{8}$ intramolecular Heck reactions, ${ }^{9}$ microwave (MW)- and photo-assisted reactions,${ }^{10}$ ring-expansion reactions,${ }^{11}$ and ringclosing metathesis. ${ }^{12}$ Recently, Soldatova et al. reported a new<smiles>[R]NC1=CC(=O)CCC1=O</smiles>

1a-t

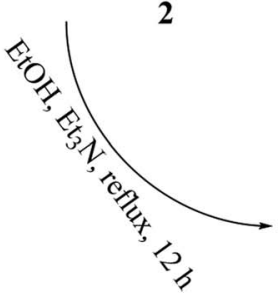

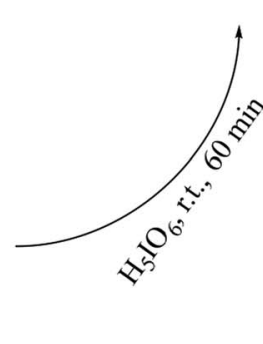

3a-t

Scheme 1 Procedure for one-pot syntheses of azocines $3 a-t$ 
Table 1 The structures of the synthesized azocine derivatives $3 a-t^{a}$<smiles>CC1(C)CC(=O)C2=C(C1)N(c1ccccc1)C(=O)c1cccc3cccc(c13)C2=O</smiles>

3a, $95 \%$<smiles>COc1ccc(OC)c(N2C(=O)C3=C(C(=O)CC(C)(C)C3)C(=O)c3cccc4cccc(c34)C2=O)c1</smiles>

3f, $87 \%$<smiles>Cc1ccc(N2C(=O)c3cccc4cccc(c34)C(=O)C3=C2CCCC3=O)cc1C</smiles>

3k, $95 \%$<smiles>COc1ccc(N2C(=O)c3cccc4cccc(c34)C(=O)C3=C2CC(C)(C)CC3=O)cc1</smiles>

3b, $90 \%$<smiles>CC1(C)CC(=O)C2=C(C1)N(c1ccc(Cl)cc1)C(=O)c1cccc3cccc(c13)C2=O</smiles>

$3 g, 92 \%$<smiles>O=C1CCCC2=C1C(=O)c1cccc3cccc(c13)C(=O)N2c1ccc(I)cc1</smiles>

3I, $90 \%$<smiles>COc1cccc(N2C(=O)c3cccc4cccc(c34)C(=O)C3=C2CC(C)(C)CC3=O)c1</smiles>

3c, $90 \%$<smiles>Cc1ccc(N2C(=O)c3cccc4cccc(c34)C(=O)C3=C2CC(C)(C)CC3=O)cc1</smiles>

3d, $95 \%$<smiles>Cc1ccc(N2NC3=C(C(=O)CC(C)(C)C3)C(=O)c3cccc4cccc(c34)C2=O)cc1C</smiles>

3e, $95 \%$<smiles>CC1(C)CC(=O)C2=C(C1)N(c1ccc(I)cc1)C(=O)c1cccc3cccc(c13)C2=O</smiles>

3h, $94 \%$<smiles>O=C1CCCC2=C1C(=O)c1cccc3cccc(c13)C(=O)N2c1ccc(Cl)cc1Cl</smiles>

$3 \mathrm{~m}, 90 \%$<smiles>CC1(C)CC(=O)C2=C(C1)N(c1ccc(Cl)cc1Cl)C(=O)c1cccc3cccc(c13)C2=O</smiles>

3i, $92 \%$<smiles>O=C1CCCC2=C1C(=O)c1cccc3cccc(c13)C(=O)N2c1cccc2ccccc12</smiles>

3n, $90 \%$<smiles>O=C1CCCC2=C1C(=O)c1cccc3cccc(c13)C(=O)N2c1ccc(Cl)cc1</smiles>

3j, $92 \%$<smiles>CC1(C)CC(=O)C2=C(C1)N(c1cccc3ccccc13)C(=O)c1cccc3cccc(c13)C2=O</smiles>

3o, $88 \%$<smiles>CCN1C(=O)c2cccc3cccc(c23)C(=O)C2=C1CC(C)(C)CC2=O</smiles>

3p, $85 \%$<smiles>CN1C(=O)c2cccc3cccc(c23)C(=O)C2=C1CC(C)(C)CC2=O</smiles>

$3 q, 85 \%$<smiles>CC1=C(C(=O)OCc2ccccc2)C(=O)c2cccc3cccc(c23)C(=O)N1c1ccc(C)c(C)c1</smiles>

$3 r, 94 \%$<smiles>COc1ccc(N2C(=O)c3cccc4cccc(c34)C(=O)C(C(=O)OCc3ccccc3)=C2C)cc1</smiles>

3s, $92 \%$<smiles>CC1=C(C(=O)OCC(C)C)C(=O)c2cccc3cccc(c23)C(=O)N1c1ccc(C)c(C)c1</smiles>

3t, $90 \%$

${ }^{a}$ Reaction conditions: enaminone (1 mmol), acenaphthoquinone (1 mmol); step 1: $\mathrm{EtOH}(4 \mathrm{~mL}), \mathrm{Et}_{3} \mathrm{~N}(1 \mathrm{mmol}), \mathrm{reflux}, 12 \mathrm{~h}$; step 2: $\mathrm{H}_{5} \mathrm{IO}{ }_{6}(1 \mathrm{mmol})$, r.t., $60 \mathrm{~min}$.

pathway for azocine derivative synthesis, with this pathway involving the reaction of an activated acetylene with a $\beta$-amino ketone. ${ }^{13}$ Most of the methods developed for azocine synthesis use expensive and inaccessible raw materials. In addition, some of the problems associated with the previous methods include the employment of metals as catalysts, harsh reaction conditions, poor product efficiency and tedious work-up. The interesting structures and important biological properties of these compounds constitute the driving force for the development of greener methods for synthesizing these compounds. In 2014, our research group developed a novel procedure for the synthesis of new azocine derivatives, with this procedure involving reactions of acenaphthoquinone with 6-aminouracil derivatives in the presence of lead(Iv) acetate. ${ }^{14}$ Although this method is interesting for forming an eight-membered azocine ring, both in terms of starting from relatively simple raw 

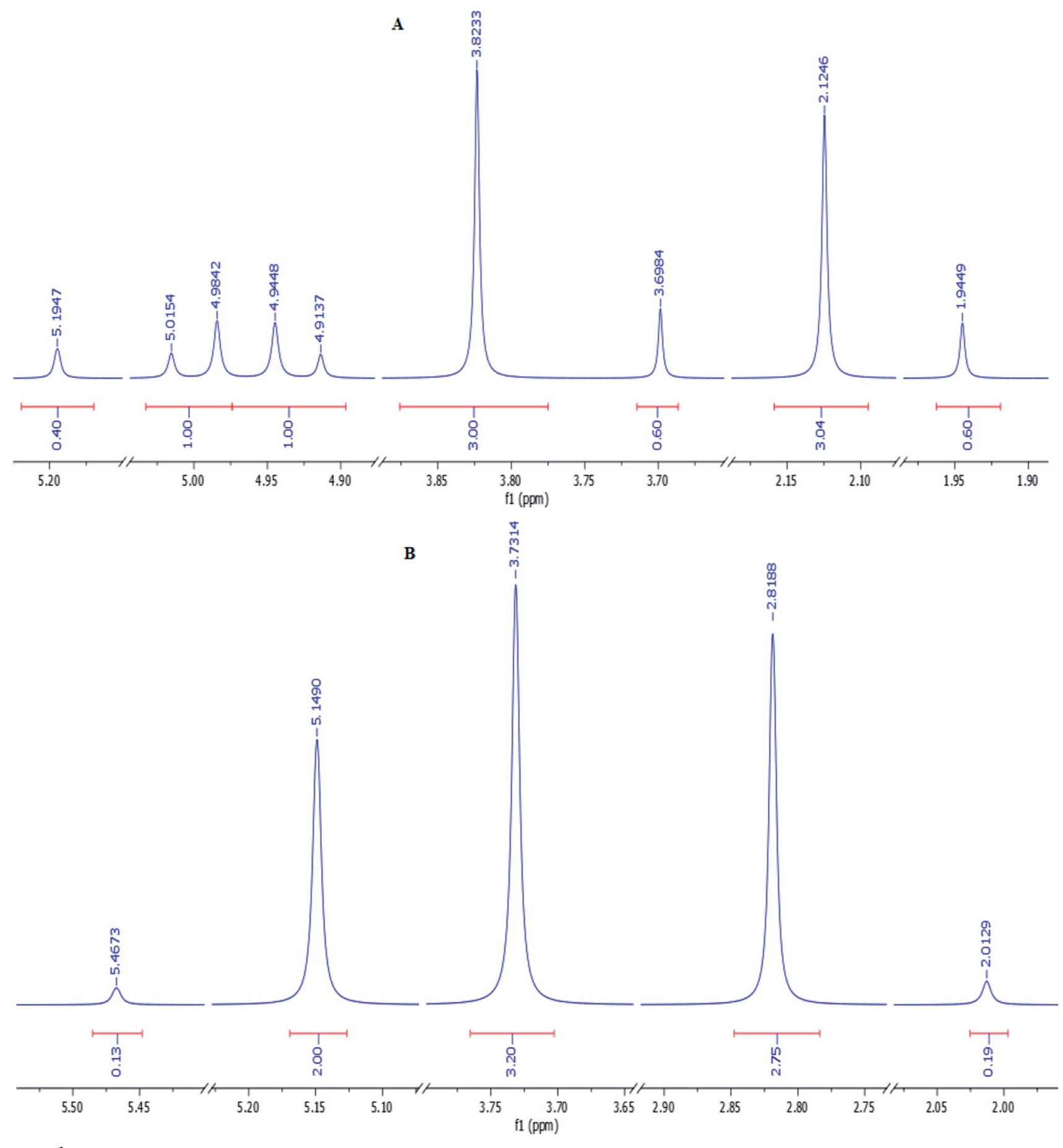

Fig. $1{ }^{1} \mathrm{H}$-NMR spectra of product 3 s recorded at room temperature (A) and $80{ }^{\circ} \mathrm{C}$ (B). The aliphatic region of each spectrum is shown.

materials and mild reaction conditions and product efficiency, the use of toxic lead metal as a catalyst has reduced its popularity. In the present study, in continuation of our studies on the oxidative cleavages of cyclic vicinal diols aimed at synthesizing potentially biologically active heterocycles, ${ }^{15}$ we developed a facile and green procedure for the synthesis of new azocine derivatives. The addition reactions of enaminones, prepared from reactions between simple and commercially available $\beta$ diketones and amines, with acenaphthoquinone followed by the metal-free $\mathrm{H}_{5} \mathrm{IO}_{6}$-mediated oxidative cleavage of the corresponding vicinal diols resulted in the azocine derivatives with excellent yields under mild reaction conditions.

\section{Results and discussion}

Initially, according to a previously reported procedure, ${ }^{16}$ enaminone derivatives 1a-t were synthesized via $\mathrm{I}_{2}$-mediated condensation reactions of amines and 1,3-dicarbonyls (for 


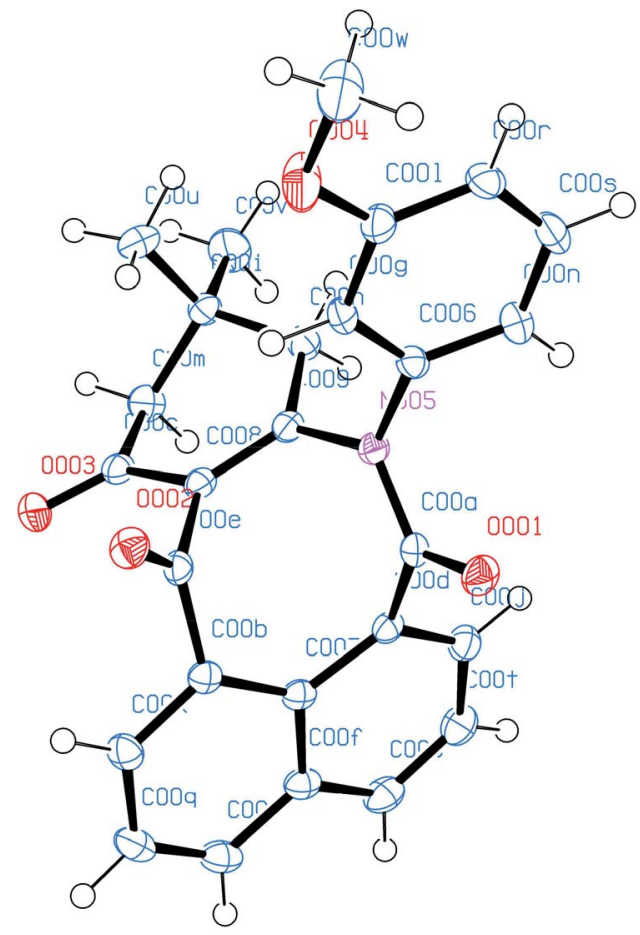

Fig. 2 ORTED representation of 3c. CCDC 1976349

details see General procedure). The synthesized enaminones 1a-t were then reacted with acenaphthoquinone 2 and converted to the corresponding azocines 3a-t in two steps (addition and oxidative-cleavage steps) as a one-pot reaction (Scheme 1).

Initial studies were done on the synthesis of product $\mathbf{3 b}$. In the addition step, which was carried out in ethanol and in the presence of $\mathrm{Et}_{3} \mathrm{~N}$ serving as a base, all of the starting materials were consumed after twelve hours of reaction time (Scheme 1, step 1). Based on our previous studies on the addition reactions of various dinucleophiles and diketones, ${ }^{14,15 a-d}$ it was predictable that vicinal diols would be the reaction products at this stage. With this precedence in mind and without carrying out any separation procedure at this stage, the corresponding intermediate was introduced into the second phase of the reaction - and by adding $\mathrm{H}_{5} \mathrm{IO}_{6}$ into the vessel, the reaction was allowed to continue for another one hour at room temperature. After now carrying out separation and purification of the final product, spectral data taken from this product confirmed it to be structure $\mathbf{3 b}$. The ${ }^{1} \mathrm{H}$-NMR spectrum of $\mathbf{3 b}$ in DMSO- $d_{6}$ exhibited three sharp singlets, at $\delta=0.62,0.84$, and 3.83 , attributed to the methyl groups. It also exhibited one sharp doublet signal $\left({ }^{3} J=16.5 \mathrm{~Hz}\right)$ at $2.03 \mathrm{ppm}$, together with a multiplet signal in the region $2.12-2.24 \mathrm{ppm}$ and a sharp doublet signal $\left({ }^{3} J=17.6 \mathrm{~Hz}\right)$ at $2.33 \mathrm{ppm}$ related to the methylene protons. Ten aromatic hydrogens were also indicated by the presence of three doublets $\left(\delta=7.14,{ }^{3} \mathrm{~J}=8.5 \mathrm{~Hz}\right),(\delta=7.41$, $\left.{ }^{3} J=8.5 \mathrm{~Hz}\right)$, and $\left(\delta=7.91,{ }^{3} J=6.9 \mathrm{~Hz}\right)$, and one triplet $(\delta=8.18$, ${ }^{3} J=8.6 \mathrm{~Hz}$ ) along with a multiplet at $\delta=7.57-7.80 \mathrm{ppm}$. The ${ }^{1} \mathrm{H}-$ decoupled ${ }^{13} \mathrm{C}$-NMR spectrum of $\mathbf{3 b}$ showed 24 distinct signals in agreement with the proposed structure. The high-resolution mass spectrum of $\mathbf{3 b}$ displayed an $[\mathrm{M}+\mathrm{H}]^{+}$peak at $\mathrm{m} / \mathrm{z}=$ 426.1700 , in agreement with the proposed structure.

Subsequently, in order to extend the scope of this reaction, the wide range of enaminones 1a-m, synthesized via the reactions of cyclic $\beta$-dicarbonyls such as dimedone and 1,3-cyclohexadione with aromatic amines, were reacted with acenaphthoquinone to produce azocines, whose structures $\mathbf{3 a - m}$ and yields are shown in Table 1. As can be seen in this table, the products $3 \mathbf{a}-\mathbf{m}$ were obtained with high efficiencies, indicating that the type, position, and number of substituents on the N-linked aromatic ring had no significant effect on the reaction rates. Moreover, the enaminones 1n-q composed of aliphatic amines such as ethyl and methyl amines as well as polycyclic amines, that is, 1-naphthylamine, were also subjected to the reaction conditions and the corresponding azocines $\mathbf{3 n - q}$ were isolated in high yields. And enaminones $\mathbf{1 r}-\mathbf{t}$, which were synthesized from the reactions of linear 1,3-dicarbonyls such as benzyl acetoacetate and isobutyl acetoacetate, were also successfully subjected to this reaction and their products $3 \mathbf{r}-\mathbf{t}$ were obtained in good yields. It is worth noting that in contrast to the ${ }^{1} \mathrm{H}$ - and ${ }^{13} \mathrm{C}-\mathrm{NMR}$ spectra of compounds $3 \mathbf{a}-\mathbf{q}$, which indicated the presence of one conformer for each compound, the spectra of products $3 \mathbf{r}-\mathbf{t}$ each
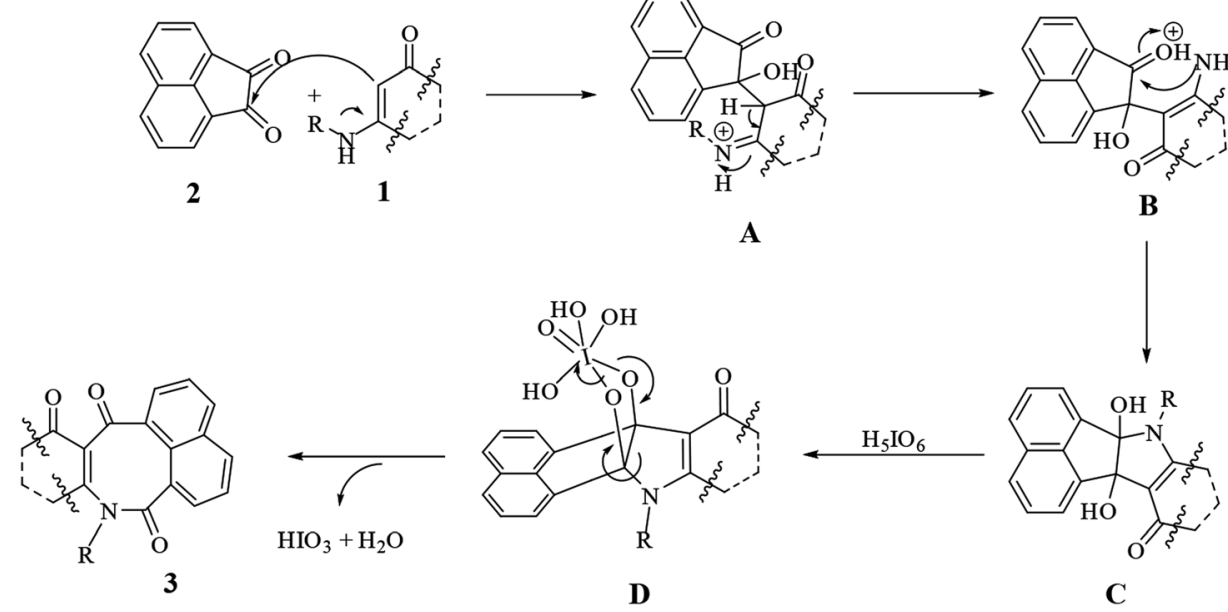

Scheme 2 Proposed mechanism for the syntheses of compounds $3 a-t$ 
showed two different conformers; this result may have been due to the structural flexibilities of $3 \mathbf{r}-\mathbf{t}$ being relatively high, and greater than those of compounds $\mathbf{3 a}-\mathbf{q}$, which have cyclic enaminone moieties. For product $3 \mathbf{s}$, the ratio of its conformers was calculated from the ${ }^{1} \mathrm{H}$-NMR spectrum to be $83: 17$. The methylene protons of the major conformer resonated as two distinct doublets due to their diastereotopic nature, but they displayed a simple pattern in the minor conformer (Fig. 1). Surprisingly, the two distinct doublets of methylene protons of the major conformer of $3 \mathbf{s}$ at room temperature converted to a sharp singlet when its ${ }^{1} \mathrm{H}-\mathrm{NMR}$ spectrum was recorded at $80^{\circ} \mathrm{C}$. Moreover, the ratio of conformers was determined from the spectrum recorded at $80{ }^{\circ} \mathrm{C}$ to be $94: 16$ (Fig. 1).

The molecular structures of all products $3 \mathbf{a}-\mathbf{t}$ were also elucidated from their IR, ${ }^{1} \mathrm{H}-\mathrm{NMR},{ }^{13} \mathrm{C}-\mathrm{NMR}$ and HRMS spectra. Finally, the structure of product $3 \mathrm{c}$ was determined unambiguously from an X-ray diffraction study (Fig. 2).

We proposed a general mechanism for the reactions, as shown in Scheme 2. According to the mechanism, first enaminone $\mathbf{1}$ attacked acenaphthoquinone $\mathbf{2}$ to form intermediate $\mathbf{A}$, followed by a rearrangement of $\mathbf{A}$ to form intermediate $\mathbf{B}$ and then vicinal diol $\mathbf{C}$. Then reacting $\mathbf{C}$ with periodic acid produced intermediate $\mathbf{D}$, which then underwent a rearrangement to form product 3 with the loss of water and iodic acid molecules.

In summary, we have developed a novel pathway for the syntheses of new azocine derivatives via the reactions of enaminones with acenaphthoquinone followed by metal-free periodic acid-mediated oxidative cleavages of the corresponding vicinal diols. The novelty of the method in combination with high yields, short reaction times, and mild reaction conditions makes this procedure an especially attractive method for the syntheses of the titled compounds.

\section{Experimental}

\section{General information}

The chemicals used in this work were purchased from Merck and Sigma-Aldrich chemical companies and were used without purification. The progress of the reactions and the purity levels of the compounds were monitored using thin layer chroma-

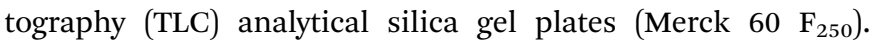
Melting points were determined using an Electro thermal 9100 apparatus. IR spectra were recorded using a Shimadzu IR-470 spectrometer with $\mathrm{KBr}$ plates. ${ }^{1} \mathrm{H}-\mathrm{NMR}$ and ${ }^{13} \mathrm{C}-\mathrm{NMR}$ spectra were recorded by using a Bruker DRX-400 AVANCE spectrometer in DMSO-d $\mathrm{d}_{6}$ as solvent.

\section{General procedure for preparing enaminones 1a-t}

In each case, 1,3-diketone ( $5 \mathrm{mmol})$, amine $(5 \mathrm{mmol}), \mathrm{I}_{2}(0.1$ $\mathrm{mmol})$, and $\mathrm{CH}_{3} \mathrm{CN}(5 \mathrm{~mL})$ were added to a reaction tube. The tube was then sealed and its contents stirred at room temperature for $1 \mathrm{~h}$. In most cases, enaminone 1 precipitated from the reaction mixture as white crystals, which were collected on filter paper and further purified by washing them with cool acetonitrile $(2 \times 2 \mathrm{~mL})$. When the product was soluble in acetonitrile, the solvent was removed under reduced pressure, with water $(10$
$\mathrm{mL})$ then added and product extracted using ethyl acetate $(3 \times 3$ $\mathrm{mL}$ ). The organic layers were collected, washed with an aqueous $\mathrm{Na}_{2} \mathrm{~S}_{2} \mathrm{O}_{3}$ solution and dried over anhydrous $\mathrm{Na}_{2} \mathrm{SO}_{4}$. After partial vaporization of solvent, the product was precipitated and the mixture was filtered to give the pure enaminone $\mathbf{1}$ as a white solid.

\section{General procedure for synthesizing azocine derivatives 3a-t}

In each case, a mixture of enaminone $3(1 \mathrm{mmol}), \mathrm{Et}_{3} \mathrm{~N}(1$ $\mathrm{mmol})$, and acenaphthoquinone $2(1 \mathrm{mmol})$ in $\mathrm{EtOH}(4 \mathrm{~mL})$ was placed in a flask and the mixture was stirred for 12 hours at reflux conditions. The progress of the reaction was monitored by performing TLC using EtOAc/n-hexane as an eluent. After completion of the reaction, the reaction mixture was cooled to room temperature and $\mathrm{H}_{5} \mathrm{IO}_{6}(1 \mathrm{mmol})$ was added to the flask and the resulting mixture was stirred for an additional 1 hour. The reaction mixture was filtered and the crude product was recrystallized from ethanol to afford the pure product 3 .

\section{Conflicts of interest}

There are no conflicts to declare.

\section{References}

1 (a) H. Rojas, M. Nidia, P. Diaz, C. Celina and O. Perez, RevistaCubanade Farmacia, 1977, 11, 249; (b) J. D. Brown, in Comprehensive Heterocyclic Chemistry, ed. A. R. Katrizky and C. W. Rees, Pergamon Press, Oxford, 1984, vol. 3, p. 57; (c) E. D. Clercq and R. J. Beraaerts, Biol. Chem., 1987, 262, 14905; (d) C. M. Bertha, M. Ellis, J. L. Flippen-Anderson, F. Porreca, R. B. Rothman, P. Davis, H. Xu, K. Becketts and K. C Rice, J. Med. Chem., 1996, 39, 2081; (e) J. Cao, J. Sun and C.-G. Yan, Org. Biomol. Chem., 2018, 16, 4170; $(f)$ P. S. Volvoikar and S. G. Tilve, Tetrahedron Lett., 2018, 59, 2567; $(g)$ A. V. Listratova and L. G. Voskressensky, Synthesis, 2017, 49, 3801.

2 (a) L. A. Arnold and R. Kiplin Guy, Bioorg. Med. Chem. Lett., 2006, 16, 5360; (b) P. A. Evans and A. B. Holmes, Tetrahedron, 1991, 47, 9131; (c) A. C. L. B. Trindade, D. C. dSantos, L. Gil, C. Marazano and R. P. dF. Gil, Eur. J. Org. Chem., 2005, 1052.

3 (a) S. Ma and Z. Gu, J. Am. Chem. Soc., 2006, 128, 4942; (b) L. Yet, Chem. Rev., 2000, 100, 2963; (c) P. A. Evans and A. B. Holmes, Tetrahedron, 1991, 47, 9131.

4 (a) P. G. Lehman, Tetrahedron Lett., 1972, 13, 4863; (b) R. M. Acheson, N. D. Wright and P. A. Tasker, J. Chem. Soc., Perkin Trans. 1, 1972, 1, 2918; (c) X. Maa, X. Zhang, G. Xie, J. M. Awad and W. Zhang, Tetrahedron Lett., 2019, 60, 151127.

5 C. A. Grob, W. Kunz and P. R. Marbet, Tetrahedron Lett., 1975, 16, 2613.

6 (a) N. J. Leonard and T. Sato, J. Org. Chem., 1969, 34, 1066; (b) N. J. Leonard, M. Oki and S. Chiavarelli, J. Am. Chem. Soc., 1955, 77, 6234; (c) N. J. Leonard and M. Oki, J. Am. Chem. Soc., 1955, 77, 6241. 
7 M. E. Garst, J. N. Bonfiglio and J. Marks, J. Org. Chem., 1982, 47, 1494.

8 (a) F. Nakatsubo, A. J. Cocuzza, D. E. Keeley and Y. Kishi, J. Am. Chem. Soc., 1977, 99, 4835; (b) T. Fukuyama, F. Nakatsubo, A. J. Cocuzza and Y. Kishi, Tetrahedron Lett., 1977, 18, 4295.

9 (a) K. C. Majumdar, B. Chattopadhyay and S. Samanta, Tetrahedron Lett., 2009, 50, 3178; (b) K. C. Majumdar, S. Mondal, D. Ghosh and B. Chattopadhyay, Synthesis, 2010, 1315; (c) H. S. Lee, S. H. Kim, T. H. Kim and J. N. Kim, Tetrahedron Lett., 2008, 49, 1773; (d) M. Jäger, H. Görls, W. Günther and U. S. Schubert, Chem. - Eur. J., 2013, 19, 2150.

10 (a) B. Alcaide, P. Almendros, C. Aragoncillo, I. Fernandez and G. Gomez-Campillos, J. Org. Chem., 2014, 79, 7075; (b) L. L. W. Cheung and A. K. Yudin, Org. Lett., 2009, 11, 1281; (c) M. R. Smith, A. J. Blake, C. J. Hayes, M. F. G. Stevens and C. J. Moody, J. Org. Chem., 2009, 74, 9372.

11 (a) M. Penning and J. Christoffers, Eur. J. Org. Chem., 2014, 2140; (b) M. Penning, E. Aeissen and J. Christoffers, Synthesis, 2015, 47, 1007; (c) L. G. Voskressensky, S. A. Kovaleva, T. N. Borisova, A. V. Listratova, A. B. Eresko, V. S. Tolkunov, S. V. Tolkunov and A. V. Varlamov, Tetrahedron, 2010, 66, 9421; (d) L. G. Voskressensky, A. A. Titov, M. S. Kobzev, R. Samavati, R. S. Borisov, L. N. Kulikova and A. V. Varlamov, Chem. Heterocycl. Compd., 2016, 52, 68; (e) H. Cho, Y. Iwama, K. Sugimoto,
S. Mori and H. Tokuyama, J. Org. Chem., 2010, 75, 627; $(f)$

K. C. Majumdar, S. Mondal, D. Ghosh and B. Chattopadhyay, Synthesis, 2010, 1315.

12 (a) L. Yet, Chem. Rev., 2000, 100, 2963; (b) A. Deiters and S. F. Martin, Chem. Rev., 2004, 104, 2199; (c) O. Pavlyuk, H. Teller and M. C. McMills, Tetrahedron Lett., 2009, 50, 2716; (d) K. C. Majumdar, S. Mondal and D. Ghosh, Synthesis, 2010, 1176.

13 S. A. Soldatova, N. M. Kolyadina, A. T. Soldatenkov and A. V. Malkova, Russ. J. Org. Chem., 2019, 55, 479.

14 M. R. Mohammadizadeh and M. Alborz, Tetrahedron Lett., 2014, 55, 6808.

15 (a) M. R. Mohammadizadeh and N. Firoozi, Tetrahedron Lett., 2010, 51, 2467; (b) M. R. Mohammadizadeh, N. Firoozi and R. Aradeh, Helv. Chim. Acta, 2011, 94, 410; (c) M. Bahramzadeh and S. Z. Taghavi, Tetrahedron Lett., 2010, 51, 5807; (d) G. H. Mahdavinia, M. R. Mohammadizadeh, N. Ariapour and M. Alborz, Tetrahedron Lett., 2014, 55, 1967; (e) S. A. Hashemi and M. R. Mohammadizadeh, ChemistrySelect, 2019, 4, 11995.

16 (a) B. Datta, M. B. M. Reddy and M. A. Pasha, Synth. Commun., 2011, 41, 2331; (b) G.-N. Zhang, X. Yuan, W. Niu, M. Zhu, J. Wang and Y. Wang, Molecules, 2018, 23, 3045; (c) K. Pradhan, S. Paul and A. R. Das, RSC Adv., 2015, 5, 12062; (d) X.-B. Chen, T.-B. Luo, G.-Z. Gou, J. Wang, W. Liu and J. Lin, Asian J. Org. Chem., 2015, 4, 921. 